\title{
Gambaran Faktor Risiko Flat Foot pada Anak Umur 6-10 Tahun di Kecamatan Sukajadi
}

\author{
Viena Nissa Mien Fadillah ${ }^{1}$, Wulan Mayasari², M. Rizal Chaidir ${ }^{3}$ \\ ${ }^{1}$ Fakultas Kedokteran Universitas Padjadjaran \\ ${ }^{2}$ Departemen Anatomi, Fisiologi, dan Biologi Sel, Fakultas Kedokteran, Universitas Padjadjaran/ \\ Rumah Sakit Umum Pusat DR. Hasan Sadikin, Bandung \\ ${ }^{3}$ Departemen Orthopedi dan Traumatologi, Fakultas Kedokteran, Universitas Padjadjaran/ \\ Rumah Sakit Umum Pusat DR. Hasan Sadikin, Bandung
}

\begin{abstract}
Abstrak
Kondisi flat foot banyak terjadi pada anak-anak. Meskipun seringkali tidak menimbulkan gejala, jika kondisi tersebut menuju tahap yang lebih serius, keadaan tersebut dapat mengganggu fungsi kaki. Sehingga dibutuhkan adanya deteksi untuk mengetahui kondisi flat foot lebih awal. Penelitian ini bertujuan untuk mengetahui gambaran faktor risiko flat foot pada anak umur enam sampai sepuluh tahun di Kecamatan Sukajadi. Metode potong-lintang deskriptif kuantitatif pada 326 anak yang telah memenuhi kriteria inklusi dan eksklusi di SD Citrawinaya, Sejahtera 1, Sukagalih 5, Sarijadi Selatan 1, dan Sukasari 1 sejak bulan September sampai Oktober 2016. Setelah mendapat persetujuan dan identitas anak, dilakukan pengukuran tinggi, berat badan serta pengecapan kaki. Status gizi diinterpretasi berdasarkan klasifikasi WHO. Sedangkan kondisi flat foot diidentifikasi menggunakan Denis grades. Dari 326 anak yang diikutsertakan, kondisi flat foot terjadi pada 129 (40\%) anak. Anak laki-laki lebih banyak mengalami flat foot $(23,78 \%)$ dibandingkan perempuan. Flat foot lebih banyak terjadi pada anak umur tujuh tahun $(9,28 \%)$, anak dengan status gizi overweight $(13,69 \%)$, dan pada anak dengan anggota keluarga yang memiliki riwayat flat foot $(26,67 \%)$. Angka kejadian flat foot pada anak di Kecamatan Sukajadi masih cukup tinggi pada kelompok yang berisiko seperti laki-laki, umur lebih muda, status gizi overweight, dan adanya riwayat flat foot pada keluarga.
\end{abstract}

Kata Kunci : Anak, Faktor risiko, Flat foot

\section{Overview of Flat Foot Risk Factors in Children Aged Six to Ten in Sukajadi District}

\begin{abstract}
Flat foot condition is high among children. Even though children with flat foot often does not arise symptoms, if the condition worsens, it can disrupt the foot's functions. Therefore an early detection of flat foot is needed. This research aimed to discover the overview of flat foot risk factors in children aged six to ten in Sukajadi district. A cross-sectional descriptive quantitative research was conducted from September-October 2016 on 326 children who fulfilled the inclusion and exclusion criteria in Citrawinaya, Sejahtera 1, Sukagalih 5, Sarijadi Selatan 1, and Sukasari 1 elementary school. After a consent and child's identity is collected, body weight, height assessment, and foot stamping were conducted. The nutritional status was interpreted based on WHO classification. Flat foot condition was identified with Denis grades. From 326 children who participated, 129 of them got flat foot (40\%). Boys tend to have flat foot more $(23,78 \%)$ compared to girls. Flat foot occurred more in seven-year-olds $(9,28 \%)$, overweight children $(13,69 \%)$, and children with family history offlat foot (26,67\%). Flat foot incidence in children in Sukajadi district is rather high in the at risk of boys, overweight children, younger children, and children with family history of flat foot.
\end{abstract}

Keywords : Children, Flat foot, Risk factor

\footnotetext{
Korespondensi:

Viena Nissa Mien Fadillah

Fakultas Kedokteran Universitas Padjadjaran

Jl. Bandung - Sumedang KM. 21 Jatinangor

Mobile : 085795554537

Email : vienanissa@gmail.com
} 


\section{Pedahuluan}

Setiap anak lahir dengan kondisi kaki datar dan lengkung kaki mulai terbentuk ketika anak menginjak umur tujuh sampai sepuluh tahun. Ketika terjadi gangguan pada proses pembentukan lengkung kaki, maka dapat mengakibatkan adanya deformitas pada kaki. ${ }^{1,2}$ Sembilan puluh persen kunjungan anak yang datang ke klinik untuk masalah kaki disebabkan oleh kondisi flat foot, meskipun sebagian besar deformitas tersebut terjadi secara fisiologis dan tidak membutuhkan pengobatan. ${ }^{3}$ Estimasi prevalensi flat foot berkisar antara 0,6-77,9\% yang terjadi akibat perbedaan kelompok umur, metode yang digunakan, dan sampel yang diikutsertakan dalam penelitian. Hasil penelitian menunjukkan flat foot terjadi sebesar $45 \%$ pada anak yang belum memasuki umur sekolah dan sebesar sepuluh persen pada anak dengan umur lebih dari sepuluh tahun. ${ }^{4}$

Flat foot merupakan kondisi ketika sebagian atau seluruh telapak kaki kontak dengan tanah. Meskipun sebagian besar kejadian flat foot terjadi dalam bentuk fisiologis, akan tetapi jika kondisi tersebut berlanjut menuju tahap yang lebih buruk, maka dapat menimbulkan gejala dan berpengaruh pada fungsi kaki penderitanya. ${ }^{5}$ Kondisi flat foot meningkat pada populasi lakilaki, umur lebih muda, status gizi overweight dan obesitas, adanya kelemahan ligamen, penduduk yang tinggal di perkotaan, adanya riwayat kejadian flat foot yang sama pada keluarga, serta penggunaan alas kaki pada masa kanak-kanak. ${ }^{6}$ Kondisi flat foot berkurang seiring pertambahan umur anak. Akan tetapi karena flat foot seringkali tidak menimbulkan gejala, maka penting untuk dilakukan program skrining khususnya untuk memeriksa kondisi flat foot. ${ }^{7,8}$ Penelitian ini betujuan untuk melihat gambaran dan proporsi faktor risiko flat foot berupa umur, jenis kelamin, status gizi, dan riwayat flat foot pada keluarga yang terjadi pada anak sekolah dasar umur enam sampai sepuluh tahun di Kecamatan Sukajadi, Kota Bandung.

\section{Metode}

Penelitian ini menggunakan metode studi potonglintang (cross-sectional) deskriptif kuantitatif dengan sampel anak sekolah dasar umur enam sampai sepuluh tahun. Data yang didapatkan pada penelitian ini merupakan data primer. Kriteria inklusi penelitian ini diantaranya merupakan anak sekolah dasar umur enam sampai sepuluh tahun di Kecamatan Sukajadi, bersedia mengikuti penelitan dari awal sampai akhir, dan hadir pada saat pengambilan data dilaksanakan. Sedangkan kriteria eksklusi penelitian ini yaitu apabila terdapat riwayat operasi pada kaki.

Proses pengambilan sampel dilakukan dengan metode cluster sampling. Dari satu Kecamatan Sukajadi, dipilih masing-masing satu sekolah dari setiap kelurahan secara acak, yaitu berasal dari Kelurahan Cipedes, Pasteur, Sukabungah, Sukagalih, dan Sukawarna dan didapatkan SDIT Citrawinaya, SDN Sukagalih 5, SDN Sejahtera 1, SDN Sukasari 1, dan SDN Sarijadi Selatan 1. Kemudian dipilih secara acak anak umur enam sampai sepuluh tahun dari kelas satu sampai empat yang telah memenuhi kriteria inklusi dan eksklusi. Proses pengambilan data dilakukan di lima SD yang terpilih setelah mendapatkan izin etik dari komisi etika penelitian Fakultas Kedokteran Universitas Padjadjaran (Nomor registrasi 0016060588) sejak bulan September sampai Oktober 2016 dengan melibatkan 354 anak.

Instrumen penelitian yang digunakan diantaranya formulir Persetujuan Setelah Penjelasan (PSP), formulir identitas anak, alat pengukur tinggi badan (microtoise), timbangan berat badan, cat poster untuk pewarna kaki, air, busa, wadah untuk menampung cat, serta kertas untuk cetakan kaki. Proses pengambilan data dimulai dengan memberikan lembar PSP dan pengisian identitas anak kepada orangtua. Dilakukan pengukuran tinggi dan berat badan untuk mendapatkan hasil status gizi anak, selanjutnya dilakukan proses pengecapan telapak kaki dengan meminta anak untuk melepaskan alas kaki, kemudian menginjakkan kaki ke busa yang mengandung cap. Setelah itu, anak diminta untuk menginjakkan kaki ke kertas yang disediakan untuk melihat hasil cetakan kaki. Status gizi anak diinterpretasi berdasarkan klasifikasi WHO dan hasil cetakan kaki di identifikasi mengalami flat foot atau tidak dengan klasifikasi Denis grades.

Data yang telah diperoleh kemudian dianalisis menggunakan Microsoft Excel 2013. Setelah dianalisis, diperoleh informasi deskriptif seperti jumlah dan persentase hasil yang selanjutnya disajikan dalam bentuk tabel.

\section{Hasil}

Jumlah anak yang dilibatkan pada penelitian ini sebanyak 354 anak. Dari 354 anak yang diikutsertakan, terdapat 28 anak yang dieksklusi. Sembilan belas diantaranya tidak diizinkan mengikuti penelitian, satu orang dengan umur kurang dari enam tahun, dan delapan orang tidak hadir pada saat pengambilan data dilaksanakan. Jumlah anak yang dapat diambil datanya dalam 
penelitian ini berjumlah 326 anak.

Jumlah anak yang mengikuti penelitian ini paling banyak berasal dari SDIT Citrawinaya (82 anak) dan paling sedikit berasal dari SDN Sarijadi Selatan 1 (42 anak), sedangkan jumlah anak yang diikutsertakan pada penelitian ini berdasarkan karakteritik masing-masing variabel diantaranya lebih banyak diikuti oleh anak perempuan (183 anak) dibandingkan anak laki-laki (143 anak), lebih banyak diikuti oleh anak umur sembilan tahun (98 anak) dan paling sedikit umur sepuluh tahun (24 anak), lebih banyak anak-anak dengan status gizi normal (199 anak) dan tidak ada anak dengan status gizi obesitas, serta lebih banyak diikuti oleh anak yang tidak memiliki riwayat keluarga dengan kondisi flat foot. Berdasarkan hasil pengamatan, jumlah anak yang mengalami flat foot yaitu sebanyak 129 (40\%) dari 326 anak, sedangkan yang tidak mengalami flat foot sebanyak 197 anak (60\%). Persentase kondisi flat foot pada masing-masing sekolah berdasarkan tabel 1 yaitu paling banyak terjadi di SDN Sejahtera 1 dan paling sedikit terjadi di SDN Sukagalih 5 .

Tabel 2 menunjukkan persentase kondisi flat foot berdasarkan karakteristik masing-masing variable, sedangkan tabel 3 menunjukkan distribusi kondisi flat foot pada keluarga anak yang mengalami kondisi flat foot dan tidak flat foot.

Tabel 1 Jumlah Kondisi Flat Foot pada Masing-masing Sekolah

\begin{tabular}{lccccc}
\hline \multicolumn{1}{c}{ Asal Sekolah } & Jumlah Siswa & \multicolumn{4}{c}{ Kejadian Flat foot } \\
& $\mathbf{n}$ & Positif & $\mathbf{\%}$ & Negatif & \% \\
\hline SDIT Citrawinaya & 82 & 28 & $6.8 \%$ & 54 & $13.2 \%$ \\
SDN Sarijadi Selatan 1 & 42 & 13 & $6.2 \%$ & 29 & $13.8 \%$ \\
SDN Sejahtera 1 & 71 & 38 & $10.7 \%$ & 33 & $9.3 \%$ \\
SDN Sukagalih 5 & 70 & 20 & $5.7 \%$ & 50 & $14.3 \%$ \\
SDN Sukasari 1 & 61 & 30 & $9.8 \%$ & 31 & $10.2 \%$ \\
\hline
\end{tabular}

Tabel 2 Jumlah Kondisi Flat Foot Berdasarkan Masing-masing Variabel

\begin{tabular}{|c|c|c|c|c|c|}
\hline \multirow{2}{*}{ Variabel } & \multirow{2}{*}{$\begin{array}{c}\text { Jumlah } \\
\text { n } \\
\end{array}$} & \multicolumn{4}{|c|}{ Kejadian Flat foot } \\
\hline & & Positif & $\%$ & Negatif & $\%$ \\
\hline \multicolumn{6}{|l|}{ Jenis Kelamin } \\
\hline Perempuan & 183 & 61 & $16.67 \%$ & 122 & $33.33 \%$ \\
\hline Laki-laki & 143 & 68 & $23.78 \%$ & 75 & $26.22 \%$ \\
\hline \multicolumn{6}{|l|}{ Usia } \\
\hline 6 Tahun & 65 & 28 & $8.62 \%$ & 37 & $11.38 \%$ \\
\hline 7 Tahun & 69 & 32 & $9.28 \%$ & 37 & $10.72 \%$ \\
\hline 8 Tahun & 70 & 29 & $8.29 \%$ & 41 & $11.71 \%$ \\
\hline 9 Tahun & 98 & 34 & $6.94 \%$ & 64 & $13.06 \%$ \\
\hline 10 Tahun & 24 & 6 & $5.00 \%$ & 18 & $15.00 \%$ \\
\hline \multicolumn{6}{|l|}{ Indeks Massa Tubuh } \\
\hline Sangat Kurus & 4 & 1 & $6.25 \%$ & 3 & $18.75 \%$ \\
\hline Kurus & 39 & 15 & $9.62 \%$ & 24 & $15.38 \%$ \\
\hline Normal & 199 & 67 & $8.42 \%$ & 132 & $16.58 \%$ \\
\hline Gemuk & 84 & 46 & $13.69 \%$ & 38 & $11.31 \%$ \\
\hline Obestitas & 0 & 0 & $0.00 \%$ & 0 & $0.00 \%$ \\
\hline \multicolumn{6}{|l|}{ Riwayat Keluarga } \\
\hline Ya & 15 & 8 & $26.67 \%$ & 7 & $23.33 \%$ \\
\hline Tidak & 311 & 121 & $19.45 \%$ & 190 & $30.55 \%$ \\
\hline
\end{tabular}


Tabel 3 Distribusi Kondisi Flat Foot pada Anggota Keluarga

\begin{tabular}{lcccc}
\hline \multirow{2}{*}{$\begin{array}{l}\text { Anggota } \\
\text { Keluarga }\end{array}$} & \multicolumn{5}{c}{$\begin{array}{c}\text { Kejadian } \\
\text { Flat foot } \\
\end{array}$} & Ya & $\%$ & Tidak & $\%$ \\
\hline Ayah & 3 & $16.67 \%$ & 0 & $0.00 \%$ \\
Ibu & 3 & $16.67 \%$ & 0 & $0.00 \%$ \\
Saudara & 1 & $5.56 \%$ & 1 & $5.56 \%$ \\
Kandung & & & & \\
Lainnya & 3 & $16.67 \%$ & 7 & $38.89 \%$ \\
\hline
\end{tabular}

\section{Pembahasan}

Berdasarkan hasil studi yang telah dilakukan sebelumnya, estimasi prevalensi flat foot pada anak berkisar antara 0,6-77,9\% akibat adanya perbedaan kelompok umur, metode pengukuran, dan sampel yang digunakan. ${ }^{4}$ Hasil penelitian ini menunjukkan persentase kondisi flat foot pada anak umur enam sampai sepuluh tahun di Kecamatan Sukajadi sebesar empat puluh persen. Hasil ini cukup berbeda jika dibandingkan dengan angka kejadian flat foot pada beberapa penelitian yang telah dilakukan di negara lain.

Berdasarkan hasil penelitian yang telah dilakukan di Tampico, Tamaulipas tahun 2014 pada anak umur sembilan sampai sebelas tahun didapatkan prevalensi flat foot sebesar 12,1\%. ${ }^{9}$ Sedangkan hasil penelitian lain yang telah dilakukan Mansoor Ali di Pakistan, prevalensi flat foot pada anak sekolah umur enam hingga sepuluh tahun yaitu seratus enam (14,8\%) anak mengalami flat foot. ${ }^{10}$ Data prevalensi flat foot yang dilakukan pada sampel dengan umur delapan belas sampai 25 tahun di Ahmednagar, India didapatkan hasil sebesar $11,25 \% .^{11}$

Perbedaan hasil yang didapatkan ini dapat terjadi akibat perbedaan metode penelitian dan karakteristik peserta yang dilibatkan dalam proses penelitian. Penelitian ini dilakukan dengan melihat hasil cetakan kaki, sedangkan penelitian lain dilakukan dengan cara melakukan pemeriksaan fisik maupun pemeriksaan menggunakan podoscope. Selain itu, terdapat perbedaan karakteristik peserta yang dilibatkan dalam penelitian seperti perbedaan kelompok umur.

Hasil penelitian ini menunjukkan bahwa kondisiflat foot lebih banyak terjadipada anak lakilaki jika dibandingkan dengan anak perempuan, yaitu sebanyak $68(23,78 \%)$ anak dari 143 anak sedangkan perempuan sebanyak 61 (16,67\%) anak dari 183 anak. Kondisi flat foot pada umur enam tahun lebih sedikit jika dibandingkan deng an umur tujuh tahun, kemudian kondisi tersebut semakin berkurang seiring pertambahan umur dari tujuh tahun menuju sepuluh tahun, dengan masing-masing persentase kejadian sebesar $8,62 \%, 9,28 \%, 8,29 \%, 6,94 \%$, dan $5 \%$. Data penelitian ini sesuai dengan penelitian yang telah dilakukan para peneliti sebelumnya bahwa prevalensi flat foot paling tinggi (46,3\%) pada anak umur enam tahun, dan paling rendah $(7,1 \%)$ umur sepuluh tahun. Enam puluh empat $(40,8 \%)$ anak laki-laki mengalami flat foot, dan hanya 42 $(19,9 \%)$ pada anak perempuan. ${ }^{12}$

Hasil penelitian yang dilakukan oleh Jen-Huei Chang di Taiwan mengenai prevalensi flat foot pada anak umur tujuh sampai dua belas tahun dan grading flat foot ditentukan berdasarkan Denis grades didapatkan hasil 1,222 dari 2,083 anak (59\%) mengalami flat foot. Persentase insiden tersebut lebih banyak terjadi pada anak laki-laki dibandingkan perempuan. Penelitian tersebut menunjukkan bahwa anak umur delapan dan sembilan tahun mengalami 1,52 dan 0,72 kali lipat kondisi flat foot jika dibandingkan dengan anak umur tujuh tahun, sedangkan anak laki-laki dua kali lipat dari anak perempuan. ${ }^{13}$

Banyaknya kondisi flat foot pada anak umur lebih muda terjadi karena umur diprediksi sebagai faktor utama yang memengaruhi terjadinya kondisi flat foot, dan kondisi flat foot akan berkurang seiring dengan pertambahan umur anak. ${ }^{1}$ Berkurangnya kondisi flat foot pada anak umur tujuh sampai sepuluh tahun pada penelitian ini dapat terjadi karena sebagian besar anak-anak mengalami perkembangan lengkung longitudinal kaki pada umur tiga sampai lima tahun. ${ }^{14}$ Hal ini juga terjadi akibat berkurangnya bantalan lemak pada lengkung medial kaki dan terjadinya penyesuaian pertumbuhan lengkung kaki secara menetap. ${ }^{8}$

Hasil penelitian yang dilakukan oleh Karen mengenai flat foot dan jenis kelamin secara signifikan menunjukkan bahwa bantalan lemak pada midfoot laki-laki lebih tebal dibandingkan dengan perempuan. Selain itu, laki-laki juga memiliki nilai Arch Index yang lebih tinggi daripada anak perempuan sehingga anak laki-laki memiliki permukaan plantar yang lebih banyak kontak dengan tanah. ${ }^{15}$ Serta adanya indikasi perkembangan medial longitudinal arch pada laki-laki lebih lambat daripada perempuan. ${ }^{13}$ Hal ini yang memungkinkan tingginya jumlah kondisi flat foot pada anak laki-laki dibandingkan perempuan

Pada penelitian ini, kondisi flat foot dilihat dari status gizi anak paling banyak terjadi pada anak dengan status gizi overweight $(13,69 \%)$ dan paling sedikit terjadi pada anak dengan status gizi underweight $(6,25 \%)$. Hal ini relevan dengan hasil penelitian lain yang melaporkan prevalensi flat foot paling tinggi terjadi pada kelompok anak 
dengan status gizi obesitas $(53,4 \%)$ dan paling rendah pada kelompok underweight $(13,1 \%){ }^{12}$ Selain itu, anak dengan status gizi obesitas dan overweight mengalami 2,66 dan 1,39 kali lipat flat foot dibandingkan dengan berat normal. ${ }^{13}$

Tingginya kondisi flat foot pada anak dengan kondisi overweight dapat berhubungan dengan bertambahnya tekanan pada lengkung kaki yang terjadi secara terus-menerus saat seseorang berjalan. ${ }^{12}$ Selain itu, status gizi overweight dan obesitas menunjukkan tingginya area kontak, rendahnya medial longitudinal arch, dan lebih besarnya tekanan pada kaki yang mengakibatkan banyaknya jumlah kondisi flat foot pada anak dengan status gizi overweight maupun obesitas. ${ }^{16}$

Data dari peneliltian ini menunjukkan bahwa delapan dari lima belas $(26,67 \%)$ anak yang mengalami flat foot memiliki riwayat anggota keluarga yang mengalami flat foot. Diantara anggota keluarga yang memiliki riwayat flat foot, persentasi kejadian flat foot pada ayah, ibu, dan saudara lainnya sebesar $16,67 \%$, sedangkan untuk saudara kandung 5,56\%.

Berdasarkan hasil penelitian yang dilakukan pada anak sekolah dasar di Anatolia menunjukkan hubungan yang signifikan antara kejadian flat foot dan riwayat keluarga. Prevalensi kejadian flat foot dengan adanya riwayat flat foot pada keluarga yaitu sebesar sembilan persen. Riwayat flat foot pada keluarga paling banyak terjadi pada anggota keluarga lainnya yaitu sebesar 42,9\%, diikuti dengan saudara kandung, ibu, dan ayah. ${ }^{17}$ Riwayat keluarga dengan flat foot juga menunjukkan hubungan yang kuat dan positif dengan kejadian flat foot pada anak (OR: 8.06; 95\% CI: 4.5515.25). ${ }^{6}$ Hal ini menunjukkan bahwa kondisi flat foot lebih banyak terjadi pada anak dengan anggota keluarga yang memiliki riwayat flat foot. Penelitian ini memiliki keterbatasan, diantaranya data riwayat anggota keluarga yang mengalami flat foot hanya didapatkan dari data identitas anak yang diberikan kepada orangtua, tidak dilakukannya pemeriksaan langsung kepada anggota keluarga untuk menilai ada tidaknya kondisi flat foot pada anggota keluarga, serta kurangnya pengetahuan orangtua mengenai kondisi flat foot yang terjadi pada anggota keluarganya disebabkan tidak munculnya tanda maupun gejala yang dirasakan.

Saran untuk penelitian selanjutnya agar dapat melakukan pemeriksaan langsung kepada anggota keluarga anak untuk mengetahui ada tidaknya kondisi flat foot pada anggota keluarga dan dapat melakukan penelitian mengenai faktor risiko flat foot lainnya.

Kesimpulan dari penelitian ini yaitu angka kejadian flat foot pada anak umur enam sampai sepuluh tahun di Kecamatan Sukajadi masih cukup tinggi terutama pada kelompok yang berisiko seperti laki-laki, umur lebih muda dan berkurang seiring pertambahan umur, status gizi overweight, dan adanya riwayat flat foot pada anggota keluarga. Kondisi ini sesuai dengan data dari beberapa penelitian sebelumnya yang menunjukkan bahwa kondisi flat foot lebih berisiko terjadi pada anak laki-laki, umur lebih muda, status gizi overweight dan obesitas, serta adanya riwayat keluarga yang mengalami kondisi flat foot.

\section{Daftar Pustaka}

1. Pfeiffer M, Kotz R, Ledl T, Hauser G, Sluga M. Prevalence of Flat Foot in Preschool-Aged Children. Pediatrics. 2006;118(2):634-9.

2. Nurzynska D, Meglio F Di, Castaldo C, Latino F, Romano V. Flatfoot in children: Anatomy of Decision Making. Ital J Anat Embryol. 2012;117(2):98-106.

3. Fabry G. Clinical Practice. Static, axial, and rotational deformities of the lower extremities in children. Eur J Pediatr. 2010;169(5):52934.

4. Evans AM, Rome K. A Cochrane Review of the Evidence for Non-Surgical Intervention for Flexible Pediatric Flat Feet. Eur J Phys Rehabil Med. 2011;47(1):69-89.

5. Haendlmayer KT, Harris NJ. Flatfoot Deformity: an Overview. Orthop Trauma. 2009;23(6):395-403.

6. Hassanin MM, Felembane FA, Nassaane MT. Flat foot among Saudi Arabian army recruits: prevalence and risk factors. 2006;12:211-7.

7. Evans AM. Screening for foot problems in children : is this practice justifiable? J Foot Ankle Res. 2012;5(18):1-10.

8. Enrique V, Fernando R, Sánchez S, Rafael J, Posada C, Carolina A, et al. Colombia Médica Prevalence offlatfoot in school between 3 and 10 years. Study of two different populations geographically and socially. 2012;43:141-6.

9. Cerón HIS, Ramírez AG, Acevedo MAR, Rodríguez PP. Childhood Obesity : a Risk Factor for Development of Flatfoot. Bol Med Hosp Infant Mex. 2015;72(1):55-60.

10. Ali M, Asadullah M, Amjad I. Prevalence of the flat foot in 6-10 years old school going children. Rawal Med J. 2013;38(4):6-8.

11. Bhoir T, Anap DB, Diwate A. Prevalence of Flat Foot among 18 -25 Years Old Physiotherapy Students: Cross Sectional Study. Indian J Basic Appl Med Res. 2014;3(4):272-8.

12. Ezema CI, Abaraogu UO, Okafor GO. Flat foot and associated factors among primary 
school children: A cross-sectional study. Hong Kong Physiother J. Elsevier Ltd; 2014;32(1):13-20.

13. Chang J-H, Wang S-H, Kuo C-L, Shen HC, Hong Y-W, Lin L-C. Prevalence of Flexible Flatfoot in Taiwanese School-aged Children in Relation to Obesity, Gender, and Age. Eur J Pediatr. 2010;169(4):447-52.

14. Atik A. Flexible flatfootness. North Clin Istanbul. 2014;1(1):57-63.

15. Mickle KJ, Steele JR, Munro BJ. Is the Foot Structure of Preschool Children Moderated by
Gender? J Pediatr Orthop. 2008;28(5):593-6. 16. Mueller S, Carlsohn A, Mueller J, Baur H, Mayer F. Influence of Obesity on Foot Loading Characteristics in Gait for Children Aged 1 to 12 Years. PLoS One. 2016;11(2):112.

17. Cetin A, Sevil S, Karaoglu L, Yucekaya B. Prevalence of Flat Foot among Elementary School Students, in Rural and Urban Areas and at Suburbs in Anatolia. Eur J Orthop Surg Traumatol. 2011;21(5):327-31. 